\title{
MONITORING FILTER PADA TANGKI AIR MENGGUNAKAN SENSOR TURBIDITY BERBASIS ARDUINO MEGA 2560 VIA SMS GATEWAY
}

\author{
${ }^{1}$ Faizal Fatturahman, ${ }^{2}$ Irawan \\ Sistem Komputer, Fakultas Teknologi Informasi, Universitas Budi Luhur \\ Jl. Raya Ciledug, Petukangan Utara, Kebayoran Lama, Jakarta Selatan 12260 \\ Telp. (021) 5853753, Fax. (021) 5866369 \\ ${ }^{1}$ faizalfatturahman@gmail.com, ${ }^{2}$ irawan@budiluhur.ac.id
}

\begin{abstract}
Clean water has a very important role in human life. If an area is difficult to get clean water for daily needs, then they have to buy water to get it. Based on these problems, research was carried out in the form of a filter tool that can be used to filter turbid water into clean water so that it can be used for daily needs and can be monitored in real-time. To be able to make these tools requires software to program so that all hardware can run, the components used are electronic components consisting of an Arduino Mega 2560, HC-SR04 Sensor, Turbidity Sensor, SIM 800L, Waterpump, and a simple water filter as a compliment. This tool works automatically, when the water tank is full of clean water, the user will receive a notification in the form of an SMS. It is hoped that the existence of this tool can help to get clean and healthy water for daily needs.
\end{abstract}

Keywords: Water Filter, HC-SR04 Sensor, Turbidity Sensor, SIM 800L V2

\section{PENDAHULUAN}

\section{LATAR BELAKANG}

Sumber air bersih pada umummya didapatkan melalui sumber mata air di dalam tanah. Pengambilan air dari dalam tanah pada dasarnya menggunakan pipa-pipa yang dipasang ke dalam tanah hingga mencapai sumber air. Untuk menarik air tersebut dari dalam tanah kepermukaan digunakan pompa air agar dapat digunakan. Pada proses penyaluran air melalui pipa ada kemungkinan terjadinya kebocoran sehingga air yang disalurkan menjadi tercampur dengan kotoran seperti tanah dan pasir. Oleh karena itu diperlukannya suatu sistem filter air tangki menggunakan sensor kekeruhan berbasis arduino via sms untuk memperoleh air jernih yang dapat digunakan. Seperti dikota kota besar khususnya Jakarta yang berada dibantaran sungai atau pinggir sungai. Mereka terkadang harus membeli untuk mendapatkan air yang bersih, bila itu dilakukan secara berulang ulang dan dilakukan terus menerus membuat pengeluaran menjadi sangat boros.

Pada penelitian ini dijelaskan sistem filter air tangki dapat dimonitor kapanpun dan dimanapun, meskipun pemilik air tangki sedang berada di luar rumah. SMS gateway yang digunakan pemilik tangki harus memiliki sim card dengan sinyal yang baik, supaya tidak terjadi delay ketika sms dikirim ke pemilik tangki.

Untuk membuat sebuah alat filter ini dibutuhkan arduino sebagai mikrokontroler, sensor HC-SR04 untuk membatasi ketinggian air, sensor turbidity untuk membaca tingkat kekeruhan pada air, pompa air sebagai pemompa air untuk dipindahkan ke filter dan tangki penampungan terakhir. SMS gateway sebagai pengirim pesan otomatis tanpa ada perintah kepada pemilik tangki air, SMS yang terkirim berupa "Tangki air bersih sudah penuh". 


\section{LANDASAN TEORI}

Untuk memahami cara kerja alat tersebut, diperlukan penjelasan berupa teori dasar yang mendukung dan berhubungan dengan alat ini. Berikut ini akan dijelaskan teori dasar hardware dan software pendukungnya.

\section{Atmega 2560 (Arduino Mega 2560)}

Arduino mega 2560 mempunyai 54 pin digital input/output, dimana 15 pin dapat digunakan sebagai output PMW, 16 pin sebagai input analog, dan 14 pin sebagai UART (Port serial Hardware), selain itu arduino mega ini juga memiliki $16 \mathrm{MHz}$ kristal osilator, tombol reset, header ICSP, koneksi USB dan jack power. Ini semua yang diperlukan untuk mendukung mikrokontroler dalam berbagai pekerjaan.

Selanjutnya untuk memulai mengaktifkan perangkat tersebut cukup dengan menghubungkannya ke computer melalui kabel USB atau power suplay atau beterai [1]. Bentuk fisik dari ATMega 2560 dapat terlihat pada Gambar 1.

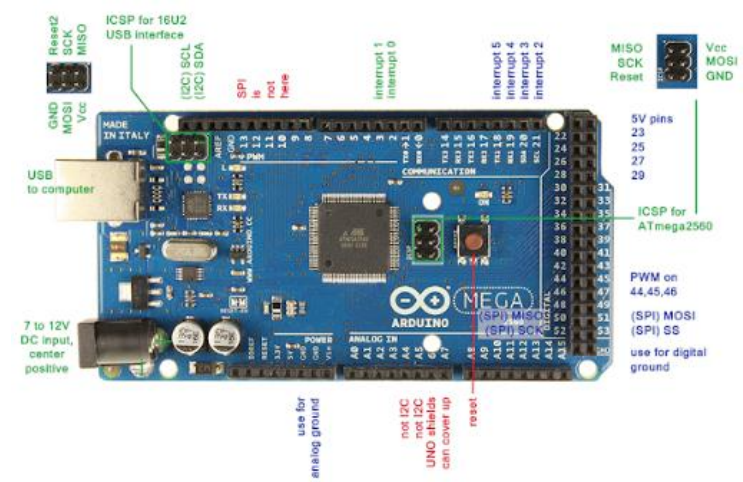

Gambar 1. Atmega 2560

Arduino Mega 2560 adalah yang mengatur dan mengendalikan semua proses agar semua bisa berjalan sesuai keinginan, serta mudah digunakan untuk merancang sistem alat ini.

\section{Sensor HC-SR04}

Sensor HC-SR04 adalah sensor yang digunakan untuk membaca ketinggian air pada alat sistem monitoring filter pada tangki air menggunakan sensor turbidity berbasis arduino mega 2560 via sms gateway. Sensor ini sangat berguna untuk mengetahui tinggin badan manusia, mengukur barang, membatasi suatu objek.

Dalam dunia robotic sangat berguna sebagai pembaca objek didepan agar bisa menghindari objek yang ada didepannya. Sensor ini sangat baik dan bagus untuk pengukuran jarak, jangkauan untuk sensor HC-SR04 ini bisa mencapai 2 - 4 meter. Bentuk dari HC-SR04 dapat dilihat pada Gambar 2.

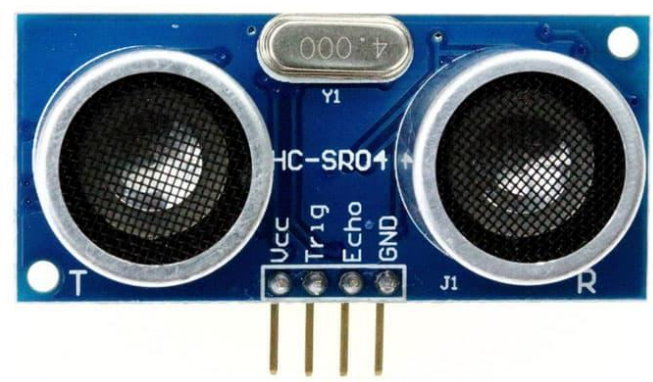

Gambar 2. Sensor HC-SR04 
Sensor HC-SR04 memliki huruf $\mathrm{T}$ dan $\mathrm{R}$ pada papan sensor tersebut, huruf tersebut adalah $\mathrm{T}$ transmitter sebagai pemancar gelombang, pembaca jarak sebuah objek, sedangkan $\mathrm{R}$ adalah Receiver sebagai penerima gelombang. Sensor HC-SR04 memiliki 4 pin [2]. Fungsi fungsi pin ditunjukkan pada Tabel 1.

Tabel 1. Fungsi fungsi pin HC-SR04

\begin{tabular}{cc}
\hline Pin & Fungsi \\
\hline VCC & 5V Power Supply. Sumber tegangan \\
\hline Trig & $\begin{array}{c}\text { Trigger. Digunakan untuk } \\
\text { membangkitkan sinyal ultrasonik. }\end{array}$ \\
\hline Echo & $\begin{array}{r}\text { Receive/Indikator mendeteksi sinyal } \\
\text { pantulan ultrasonik. }\end{array}$ \\
\hline GND & Ground. sumber tegangan negatif. \\
\hline
\end{tabular}

Sensor ini dipasang pada 2 tangki penampungan, tangki penampungan pertama terpasang bersama sensor turbditiy, ketika sensor pertama membaca hingga sensor turbidity membaca kekeruhan air, setelah itu sensor kedua membaca batas ketinggian air pada tangki air bersih.

\section{SIM $800 \mathrm{~L}$ V2}

SIM800 adalah salah satu modem GSM/GPRS yang bekerja di empat band frekuensi yakni 850, 900, 1800, dan 1900 MHZ. Sedangkan GPRS-nya mengadopsi teknologi multi slot class 12/10 dan mendukung skema coding GPRS CS1-CS4.Selain itu, dengan tambahan fitur Bluetooth, radio FM serta ukurannya yang kompak menjadikan modul ini alternatif utama pengganti modul SIM900 yang legendaris [3]. Bentuk fisik SIM 800L V2 dapat ditunjukkan pada Gambar 3.

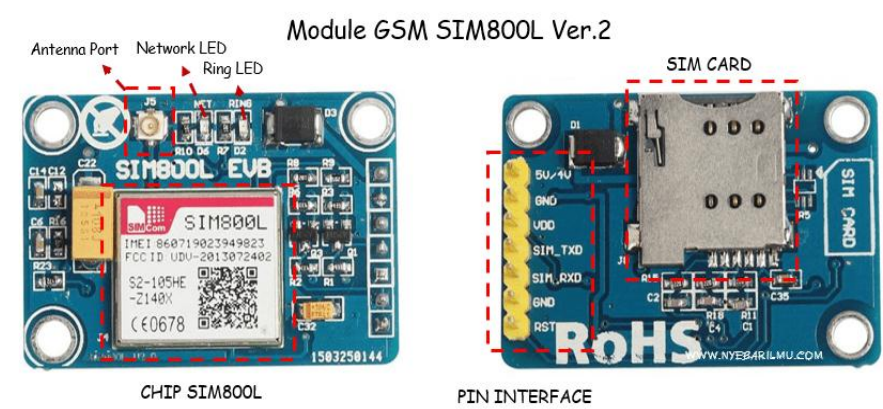

Gambar 3. SIM 800L v2

Modul ini bekerja pada saat sensor HC-SR04 sudah membaca ketinggian air hingga mencapai batasnya, modul ini adalah sebagai jalur komunikasi antara mikrokontroler dengan pemilik tangki air bila sudah air dalam tangki sudah bersih dan penuh pemilik tangki akan menerima sebuah pesan singkat "Tangki Air Bersih Sudah Terisi Penuh" sms ini akan dikirim sekali tanpa harus memerintahnya karena alat ini akan otomatis berjalan ketika di nyalakan.

Adapun fungsi fungsi pin pada SIM800L V2 ditunjukkan pada Tabel 2.

Tabel 2. Fungsi pin SIM800L v2 


\begin{tabular}{cl}
\hline Pin & \multicolumn{1}{c}{ Fungsi } \\
\hline 5V & Sumber tegangan \\
\hline GND & Tegangan negatif \\
\hline VDD & $\begin{array}{l}\text { Tegangan referensi level serial } \\
\text { TXD RXD }\end{array}$ \\
\hline SIM_TXD & Sinyal pengirim \\
\hline SIM_RXD & Sinyal penerima \\
\hline GND & Tegangan negatif \\
\hline Reset & $\begin{array}{l}\text { Reset sebagai memulai ulang atau } \\
\text { mereboot SIM800L }\end{array}$ \\
\hline
\end{tabular}

\section{Sensor Turbidity}

Sensor Turbidity adalah sensor modul yang berkerja untuk membaca kekeruhan pada air, pada dasarnya partikel kekeruhan tidak bisa dilihat oleh mata langsung. Semakin banyak partikel dalam air menunjukan tingkat kekeruhan air juga tinggi [4]. Semakin tinggi tingkat kekeruhan air akan diikuti oleh perubahan dari tegangan output sensor. Adapun bentuk fisik dari sensor turbidity dapat dilihat pada Gambar 4.

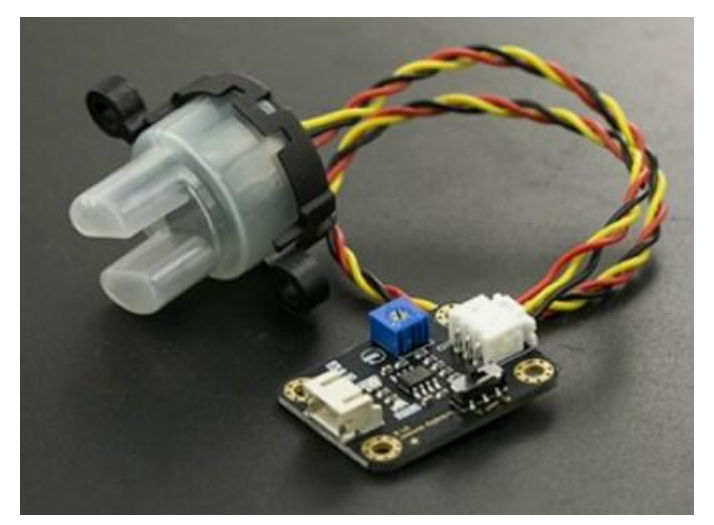

Gambar 4. Sensor Turbidity

Spesifikasi sensor turbidity :

- Tegangan Operasi: 5V DC

- Arus saat beroperasi: 40mA (MAX)

- Waktu Respons: <500ms

- Resistensi isolasi: $100 \mathrm{~m}$ (min)

- Metode Output:

- Output analog: 0-4.5V

- Output Digital: Sinyal level Tinggi / Rendah (Anda dapat menyesuaikan nilai ambang dengan menyesuaikan potensiometer)

- Suhu Operasional: $5^{\circ} \mathrm{C} \sim 90^{\circ} \mathrm{C}$

- Suhu Penyimpanan: $-10{ }^{\circ} \mathrm{C} \sim 90{ }^{\circ} \mathrm{C}$

- Berat: $30 \mathrm{~g}$

- Dimensi Adaptor: $38 \mathrm{~mm} * 28 \mathrm{~mm} * 10 \mathrm{~mm} / 1.5$ inci $* 1.1$ inci $* 0.4$ inci

5. Relay 4 Channel

Relay adalah Saklar (Switch) yang dioperasikan secara listrik dan merupakan komponen Elektromekanikal (Electromechanical) yang terdiri dari 2 bagian utama yakni Elektromagnet (Coil) dan Mekanikal (seperangkat Kontak Saklar/Switch). Relay menggunakan Prinsip Elektromagnetik untuk menggerakkan kontak saklar sehingga dengan arus listrik yang kecil (low power) dapat menghantarkan listrik yang bertegangan lebih tinggi [5][6]. 
Relay ini bekerja sebagai mematikan dan menyalakan semua pompa air sehingga berfungsi dengan baik ketika digunakan, pompa yang digunakan ada 3 pompa. Bentuk fisik dari relay dapat dilihat pada Gambar 5.

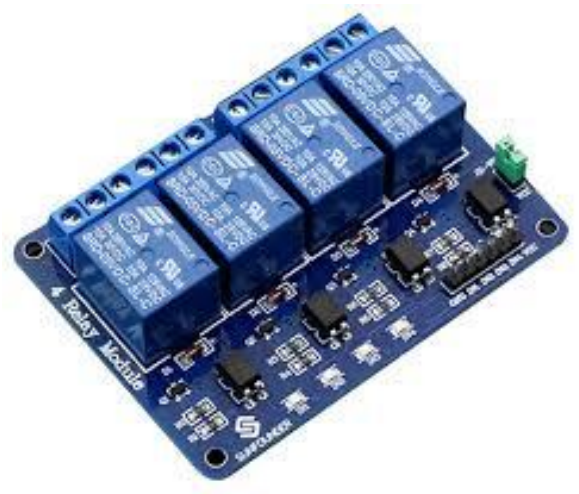

Gambar 5. Relay 4 channel

Spesifikasi relay :

- 5V 4-Channel Relay interface board, arus sink $15 \mathrm{~mA}$ - bisa langsung dari pin mikrokontroler.

- Kapasitas relay, AC250V 10A ; DC30V 10A.

- Interface standard TTL logic langsung dikendalikan mikrokontroler (Arduino, 8051, AVR, PIC, DSP, ARM, ARM, MSP430, TTL logic).

- Rangkaian proteksi (isolasi, arus kickback) sudah termasuk di dalamnya - aman dan siap digunakan.

- LED indikator untuk menandakan channel yang aktif.

- Dimensi 8 × 4.8 × $2 \mathrm{~cm}$.

6. Pompa Air

Pompa air adalah alat yang digunakan untuk memindahkan air dari ketempat satu ketempat yang lainnya melalui selang [7]. Pada pompa air ada lubang untuk masuknya air dan keluarnya air. Prinsipnya adalah menambahkan energi pada air secara terus menerus sehingga air bisa berpindah dengan kecepatan yang dihasilkan pada pompa air. Gambar pompa air dapat ditunjukka pada Gambar 6.

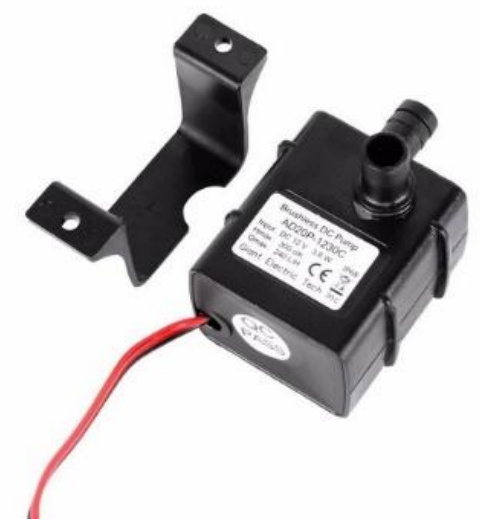

Gambar 6. Pompa Air

Pompa air ini berkerja ketika mendapatkan tegangan $12 \mathrm{v}$ sehingga dibutuhkan power supply untuk bisa menggunakan alat ini, bila diberi tegangan langsung ke mikrokontroller alat ini tidak akan kuat dikarekan arus yang dibutuhkan harus besar. Inlet dan outlet yang digunakan untuk selang ukuran $8 \mathrm{~mm}$ setara dengan selang pada akuarium. Untuk penggunannya pompa ini di tenggelamkan seluruhnya. 
Pompa air ini diklaim dapat berkerja 30.000 tetapi penggunannya harus ditenggelamkan di air, jika tidak akan mudah rusak ketika tidak ada air yang ditarik atau dipindahkan.

\section{Power Supply (Catu Daya)}

Power supply adalah sebagai sumber daya dalam bentuk tegangan [8]. Tegangan yang disalurkan ke rangkaian lainnya untuk mengaktifkan rangkain-rangkain lainnya agar bisa digunakan, karena semua komponen tiap sumber tegangannya tidak semua $5 \mathrm{~V}$, ada yang menggunakan $3,3 \mathrm{~V}$, dan $12 \mathrm{~V}$, dibutuhkanya power supply sebagai sumber tegangan $12 \mathrm{~V}$. Bentuk fisik dapat dilihat pada Gambar 7.

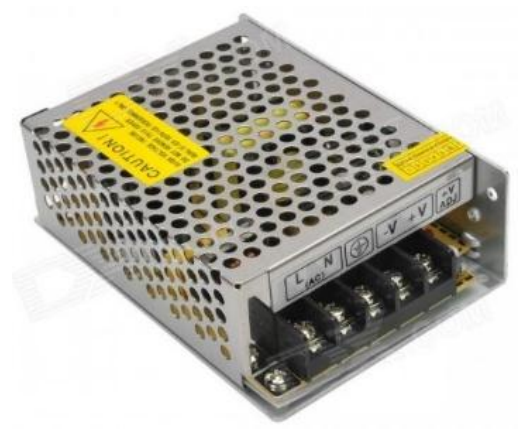

Gambar 7. Power Supply (Catu Daya)

8. Software Arduino IDE

Software Arduino IDE software untuk memprogram mikrokontroler supaya komponen bisa berjalan sesuai program. IDE adalah sebuah software yang berperan untuk menulis program, mengcompile menjadi kode biner dan meng-upload ke dalam memory microcontroller. Software ini dapat di install pada Windows, Mac OS, dan Linux. Software ini dipermudah dengan adanya Library, dengan adanya library kita tidak perlu membuat dari 0 , cukup upload library yang sudah di download ke software arduino, kita hanya merubah atau memodif sedikit agar sesuai keinginan. Software arduino dapat dilihat pada Gambar 8.

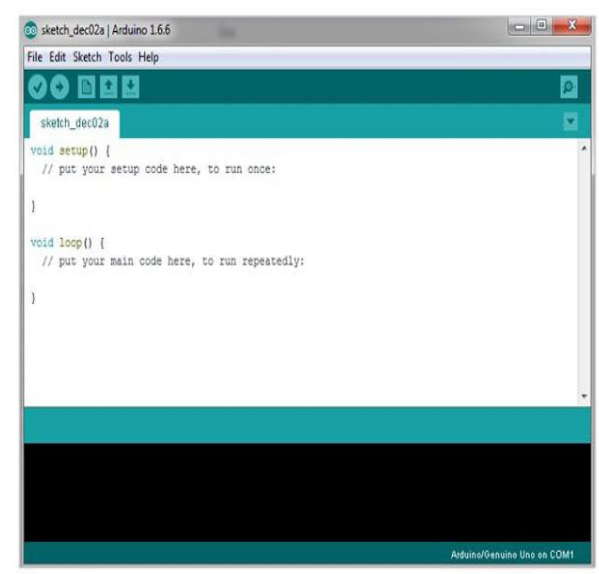

Gambar 8. Software Arduino IDE [9]

\section{Software Proteus}

Software ini sangat membantuk kita untuk mengetahui dasar dasar elektronika sampai pada pengaplikasinnya pada mikrokontroller. Software ini juga sebagai media untuk belajar mendesain PCB dan melakukan pengujian rangkaian sebelum dibuat ke dalam PCB [10]. Ketika PCB akan dibuat membutuhkan sebuah skematik simulasi, software ini pun memiliki fitur simulasi skematik untuk PCB 
yang dibuat sudah benar atau tidak. Software ini pun sudah memiliki beberapa contoh aplikasi desain. Bentuk fisik software proteus ditunjukan pada Gambar 9.

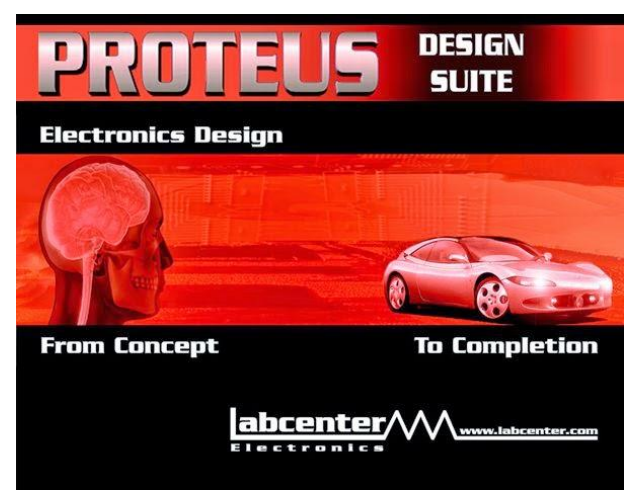

Gambar 9. Software Proteus

\subsection{Permasalahan}

Dengan bertambahnya jumlah populasi penduduk di suatu daerah, kebutuhan akan air bersih semakin lama semakin meningkat. Seringkali untuk mendapatkan air bersih untuk kebutuhan seharihari, mereka harus membeli air tersebut untuk mendapatkannya.

\subsection{Rencana Pemecahan}

Berdasarkan permasalahan di atas, penelitian ini bertujuan untuk membuat alat monitoring air pada tangki agar terjaga kebersihan airnya dengan menggunakan arduino mega sebagai mikrokontrollernya dan turbidity sebagai sensor pembaca kekeruhan air.

\subsection{Tujuan Penelitian}

1. Memberikan solusi bagaimana mendapatkan air yang bersih dengan filter air sederhana secara otomatis menggunakan sensor turbidity.

2. Menciptakan alat yang dapat di monitor dan dikendalikan dari jarak jauh dengan SMS Gateway.

\section{METODOLOGI PENELITIAN}

Dalam pembuatan racangan alat ini dibutuhkan sebuah gambaran untuk menjelaskan langkahlangkah atau alur cara kerja alat. Penjelasan berupa dari gambar proses kerja sebuah sistem merupakan gambar dari diagram alur sistem yang akan dibuat. Tujuan dari pembuatan diagram alur adalah untuk mempermudah pembuat sistem itu sendiri dan untuk memahami langkah-langkah serta cara kerja sistem yang dibuat.

Perancangan tiap-tiap blok mempermudah proses pengukuran dan untuk menghindari kesulitan jika terjadi kerusakan serta kesalahan sistem dari alat tersebut agar dapat berjalan secara efektif. Adapun diagram blok dapat dilihat pada Gambar 10. 


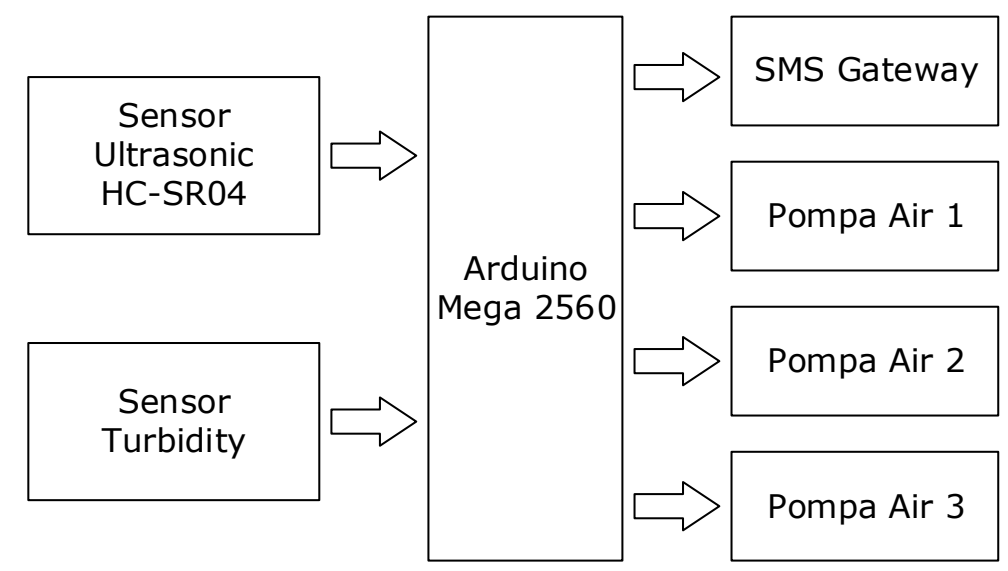

Gambar 10. Diagram Blok

Dari diagram blok di atas dijelaskan bahwa input yang masuk pada mikrokontroller akan memberikan informasi kepada pengguna melalui modul SIM800L yang berupa pesan singkat air keruh yang akan dideteksi oleh sensor Turbidity.

Hal itu berdasarkan program yang sudah diberikan pada arduino. Disini dapat dilihat pentingnya peranan mikrokontroller, yang mana mikrokontroller akan mengolah input dan mengatur output. Jadi, mikrokontroller merupakan pengendali utama pada sistem kerja alat tersebut.

1. Input

Pada bagian Inpu tini terdiri dari Sensor HC-SR04, dan Sensor Turbidity.

a. Sensor HC-SR04

Berfungsi sebagai pembatas ketinggian air di tangki penampungan kedua dan ketiga

b. Sensor Turbidity

Sensor Turbidity ini yang akan membaca kondisi air di tangki penampungan air yang keruh atau air yang bersih.

2. Proses

Pada bagian proses menggunakan satu buah Arduino Mega 2560 masing-masing melakukan proses sesuai dengan perintah yang telah diprogram beserta sensor HC-SR04, sensor Turbidity air sedang keruh atau bersih dan ketinggian air di dalam tangki penampungan.

3. Output

Terdiri notifikasi SMS, dan pompa air.

a. Notifikasi SMS

Notifikasi sms berupa pesan singkat akan memberikan informasi kepada pengguna keadaan air di tangki penampungan sedang keruh dan posisi tangki penampungan akhir telah penuh.

b. Pompa air

Pompa air sebagai alat untuk memindahkan air dari tangki 1 ke penampungan pertama, kedua, dan ketiga.

\subsection{Cara Kerja Alat}

Cara kerja alat ini menggunakan sensor turbidity, sensor HC-SR04, filter air sederhana, pompa air, arduino mega, dan SIM800L v2 SMS gateway. Tahapan awal air akan di tampung di tangki penampungan pertama yang berisi air keruh. Kemudian air yang keruh dipindahkan oleh pompa air ke filter air sederhana, air yang sudah melewati filter air sederhana akan masuk ke tangki penampungan kedua hingga air mecapai batas yang dibaca sensor HC-SR04 pertama untuk ketinggian air. Sensor turbidity akan membaca apakah air masih keruh atau sudah tidak keruh, jika air masih keruh akan dipindahkan kembali oleh pompa air ke filter air sederhana berulang ulang hingga sensor turbidity tidak membaca air keruh. Air yang sudah bersih akan dipindahkan oleh pompa ketiga masuk ke tangki penampungan ketiga, hingga batas air mencapai titik yang dibaca sensor HC-SR04 kedua. SIM800L v2. 
Sms gateway mengirim pesan untuk monitoring sensor HC-SR04 yang berada di tangki penampungan air yang sudah bersih. Jika sudah bersih pemilik tangki akan menerima berupa notifikasi sms "Tangki Air Bersih Sudah Terisi Penuh".

Dengan dirancangnya alat sistem monitoring filter pada tangki air menggunakan sensor turbidity berbasis arduino mega 2560 via sms gateway, diharapkan pemilik tangki air dapat mengetahui informasi ketika air yang sudah difilter bersih dan terisi penuh secara otomatis tanpa diperintahakan terlebih dahulu sehinggan menjadi efisien.

\section{HASIL DAN PEMBAHASAN 4.1 Pengujian Sensor HC-SR04}

Komunikasi antara Arduino dengan sensor ping dijembatani oleh jalur komunikasi serial Trig pada pin 5 dan Echo pada pin 6 pada sensor ping 1, Pin 3 dihubungkan dengan Trig dan Echo pada Pin 2 pada arduino mega 2560. Berikut akan dijelaskan pengujian konfigurasi Sensor Ping agar berfungsi dengan baik.

Pada tahap pertama selesaikan wiring antara sensor ping dengan arduino dengan pin - pin yang sudah ditentukan. Setelah itu buka software arduino, dan upload program pengujian Sensor Ping, dan buka serial monitor. Setelah itu akan muncul latitude dan longitude seperti terlihat pada Gambar 11.

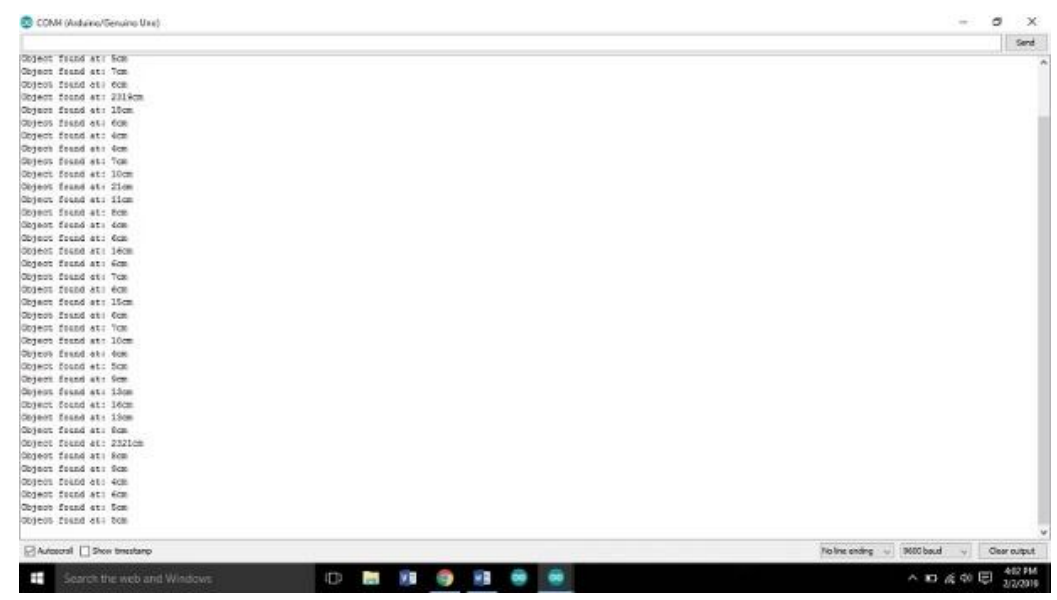

Gambar 11. Serial Monitor Sensor HC-SR04

\subsection{Pengujian SIM800L V2}

Pengujian ini dilakukan untuk memastikan sistem SMS melalui modul SIM800L V2 bekerja sesuai dengan yang diatur pada perancangan software sebelumnya, sangat penting untuk diperhatikan agar alat dapat memberikan informasi ke pengguna saat air sudah penuh. Di bawah ini Gambar 12 adalah tampilan dari isi pesan yang diberikan saat alat aktif dan pemberitahuan bahwa air sudah penuh. 
Vol 7 No. 2 , 2019

(C)2019 Ilmu Komputer Unila Publishing Network all rights reserved

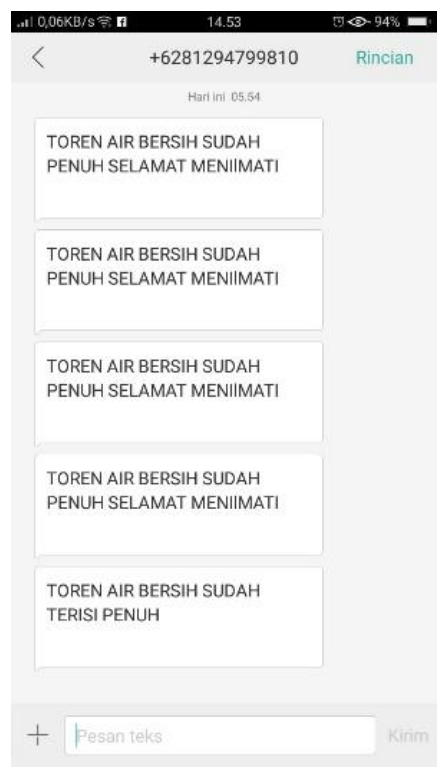

Gambar 12. Notifikasi SMS

\subsection{Pengujian Sensor Turbidity Pada Air Kopi}

Pengujian ini dilakukan untuk menguji coba sensor Turbidity, apakah sensor tersebut berfungsi atau tidak. Pada pengujian ini sensor Turbidity diuji coba mengukur kadar kekeruhan dalam air menggunakan air bening dan air kopi. Hasil dari percobaan dapat dilihat pada Tabel 3 dan 4.

Tabel 3. Pengujian pada air bersih

\begin{tabular}{ccc}
\hline No & Waktu (detik) & Hasil \\
\hline 1 & 5 & Bening \\
\hline 2 & 10 & Bening \\
\hline 3 & 20 & Bening \\
\hline 4 & 40 & Bening \\
\hline 5 & 60 & Bening \\
\hline
\end{tabular}

Tabel 4. Pengujian pada air kopi

\begin{tabular}{ccl}
\hline No & Waktu (detik) & Hasil \\
\hline 1 & 5 & Keruh \\
\hline 2 & 10 & Keruh \\
\hline 3 & 20 & Keruh \\
\hline 4 & 40 & Keruh \\
\hline 5 & 60 & Keruh \\
\hline
\end{tabular}

\section{KESIMPULAN}

Dalam perancangan alat ini didapatkan beberapa kesimpulan yang diantaranya sebagai berikut:

1. Sensor HC-SR04 bekerja dengan baik saat air mencapai batas yang ditentukan.

2. Sensor Turbdiity dapat mendeteksi kekeruhan air yang disimulasikan dengan simulator filter air dengan baik.

3. Modul SIM800L V2 dapat bekerja sesuai apa yang diprogram, dimana modul SIM800L V2 sebagai jalur komunikasi antara Arduino Mega 2560 dan Handphone pengguna.

\section{DAFTAR PUSTAKA}


[1] A. Iskandar, Muhajirin, Lisah, "Sistem Keamanan Pintu Berbasis Arduino Mega", 3(2), pp. 99$104,2017$.

[2] D.K. Fisher, R. Sui, “An inexpensive open-source ultrasonic sensing system for monitoring liquid levels”, Agricultural Engineering International: CIGR Journal, vol 15, pp. 328-334, 2013.

[3] M. Saleh, M. Haryanti, "Rancang Bangun Sistem Keamanan Rumah Menggunakan Relay", 8(3), pp. 181-185.

[4] A. Fairuz and M. Zubir, "Turbidimeter Design and Analysis: A Review on Optical Fiber Sensors for the Measurement of Water Turbidity”, Sensors, vol.9, 8311-8335, 2009.

[5] Windarto and M. Haekal, "Aplikasi Pengatur Lampu Lalu Lintas Berbasis Arduino Mega 2560 Menggunakan Light Dependent Resistor (LDR) dan Laser”, Jurnal Arsitron, vol 3, pp. 98-107, 2012.

[6] A. Shoman Muzaki, A. Hendra, W. Pamungkas, "Aplikasi Sensor Cahaya Untuk Alarm Anti Pencuri”, Jurnal Infotel, vol. 3, No. 2, 2011.

[7] Andrizala, D. Yendri, "Pengendali Pompa Pengisi Galon Air Berbasis Sensor Waterflow dan Mini PC”, Jurnal Resti, vol. 1 No. 2, 2017.

[8] Syukriyadin, "Sistem Proteksi Arus Bocor Menggunakan Earth Leakage Circuit Breaker Berbasis Arduino", Jurnal Rekayasa Elektrika vol. 12, No. 3, pp. 111-118, 2016.

[9] V. Sonandkar, "Power Measurement Using Arduino For Effective Demand Response", IEEE 6th International Conference on Power Systems (ICPS), New Delhi, 2016.

[10] J.M.Hughes, “Arduino: A Technical Reference A Handbook for Technicians, Engineers, and Makers”, O’Reilly, 2016. 